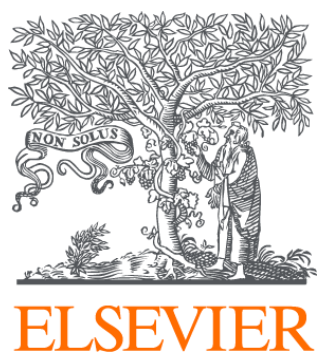

Since January 2020 Elsevier has created a COVID-19 resource centre with free information in English and Mandarin on the novel coronavirus COVID-

19. The COVID-19 resource centre is hosted on Elsevier Connect, the company's public news and information website.

Elsevier hereby grants permission to make all its COVID-19-related research that is available on the COVID-19 resource centre - including this research content - immediately available in PubMed Central and other publicly funded repositories, such as the WHO COVID database with rights for unrestricted research re-use and analyses in any form or by any means with acknowledgement of the original source. These permissions are granted for free by Elsevier for as long as the COVID-19 resource centre remains active. 


\section{Corrigendum to "Timing of sentinel node biopsy independently predicts disease-free and overall survival in clinical stage I-II melanoma patients: A multicenter study of the Italian Melanoma Intergroup (IMI)" [Eur J Canc 137 (2020). Pages 30-39]}

Mario Mandalà ${ }^{\mathrm{a}, *}$, Francesca Galli ${ }^{\mathrm{b}}$, Roberto Patuzzo ${ }^{\mathrm{c}}$, Andrea Maurichi ${ }^{\mathrm{c}}$, Simone Mocellin ${ }^{\mathrm{d}, \mathrm{e}}$, Carlo R. Rossi ${ }^{\text {d,e }}$, Eliana Rulli ${ }^{\mathrm{b}}$, Maria Montesco ${ }^{\mathrm{f}}$, Pietro Quaglino ${ }^{\mathrm{g}}$, Virginia Caliendo ${ }^{\mathrm{h}}$, Vincenzo De Giorgi ${ }^{\mathrm{i}}$, Barbara Merelli ${ }^{\mathrm{a}}$, Corrado Caracò ${ }^{\mathrm{j}}$, Dario Piazzalunga ${ }^{\mathrm{k}}$, Alice Labianca ${ }^{\mathrm{a}}$, Simone Ribero ${ }^{\mathrm{f}}$, Rebecca Senetta ${ }^{1}$, Andrea Gianatti ${ }^{\mathrm{m}}$, Barbara Valeri ${ }^{\mathrm{n}}$, Daniela Massi ${ }^{\circ}$, Paolo A. Ascierto ${ }^{\mathrm{p}}$, Mario Santinami ${ }^{c}$, Italian Melanoma Intergroup (IMI)

\footnotetext{
${ }^{\text {a }}$ Unit of Medical Oncology, Papa Giovanni XXIII Hospital, Bergamo, Italy

${ }^{\mathrm{b}}$ Methodology for Clinical Research Laboratory, Istituto di Ricerche Farmacologiche Mario Negri IRCCS, Milan, Italy

${ }^{\mathrm{c}}$ Melanoma and Sarcoma Unit, Department of Surgery, IRCCS Fondazione Istituto Nazionale dei Tumori, Milan, Italy

${ }^{\mathrm{d}}$ Unit of Surgery, Veneto Institute of Oncology - IOV, Italy

${ }^{\mathrm{e}}$ University of Padua, Italy

${ }^{\mathrm{f}}$ Pathological Anatomy and Histology, Veneto Institute of Oncology - IOV, Istituto di Ricovero e Cura a Carattere Scientifico, Padua, Italy

${ }^{\mathrm{g}}$ Dermatologic Clinic, Department of Medical Sciences, University of Turin Medical School, Turin, Italy

${ }^{\mathrm{h}}$ Department of Surgery, University of Turin Madical Scholl, Italy

${ }^{\mathrm{i}}$ Department of Dermatology, University of Florence, Italy

${ }^{\mathrm{j}}$ Istituto Nazionale Tumori IRCCS Fondazione 'G. Pascale', Naples, Italy

${ }^{\mathrm{k}}$ Unit of Surgery, Papa Giovanni XXIII Hospital, Bergamo, Italy

${ }^{1}$ Pathology Division, 'Città della Salute e della Scienza di Torino' University Hospital, Turin, Italy

${ }^{\mathrm{m}}$ Unit of Pathology, Papa Giovanni XXIII Hospital, Bergamo, Italy

${ }^{\mathrm{n}}$ Department of Pathology and Laboratory Medicine, IRCCS Fondazione Istituto Nazionale dei Tumori di Milano, Milan, Italy

${ }^{\circ}$ Histopatology and Molecular Diagnostics, Careggi University Hospital, Florence, Italy

${ }^{\mathrm{p}}$ Unit Melanoma, Cancer Immunotherapy and Innovative Therapies, Istituto Nazionale Tumori IRCCS Fondazione 'G. Pascale', Naples, Italy
}

\footnotetext{
DOI of original article: https://doi.org/10.1016/j.ejca.2020.07.001.

* Corresponding author: Unit of Medical Oncology, Department of Oncology and Haematology, Papa Giovanni XXIII Cancer Center Hospital, Piazza OMS 1, 24100, Bergamo, Italy.

E-mail address: mmandala@asst-pg23.it (M. Mandalà).
} 
The authors regret that the affiliation details are incorrect for Authors Simone Mocellin and Carlo R. Rossi. The correct affiliation details are given below.

Simone Mocellin ${ }^{\mathrm{d}, \mathrm{e}}$

${ }^{\mathrm{d}}$ Unit of Surgery, Veneto Institute of Oncology - IOV

${ }^{\mathrm{e}}$ University of Padua, Italy
Carlo R. Rossi ${ }^{\mathrm{d}, \mathrm{e}}$

${ }^{\mathrm{d}}$ Unit of Surgery, Veneto Institute of Oncology - IOV

${ }^{\mathrm{e}}$ University of Padua, Italy

The authors would like to apologise for any inconvenience caused. 